\title{
Memory and Justification: Hookway and Fumerton on Scepticism*
}

\section{Carlos J. Moya and Tobies Grimaltos}

In his 2000 paper, Hookway intends to argue that Fumerton's Principle of Inferential Justification does not have the sceptical consequences that Fumerton sees into it. We think Hookway is right in holding this. However, after commenting on his main considerations for this thesis, we shall develop an independent line of argument which reinforces the same conclusion.

1. Fumerton's Principle concerns justification of inferential beliefs, that is, of beliefs held on the basis of other beliefs or of some body of evidence. To recall, the principle is as follows:

PIJ: To be justified in believing one proposition $P$ on the basis of another proposition $E$, one must be (1) justified in believing $E$ and (2) justified in believing that $E$ makes probable $P$ (Fumerton 1995: 36).

Fumerton contends that, if we accept this seemingly plausible principle, the justifiedness of a large number of our beliefs will be destroyed or seriously impaired. One way in which the supposed 
sceptical threat arises is as follows: clause (1) of the PIJ gives rise to a regress, the kind of regress which foundationalism has intended to stop by appealing to noninferentially justified beliefs; but clause (2) generates a second regress, a more damaging one. Suppose, in effect, that someone believes that $E$ makes probable $P$. Is he justified in believing this? It is unlikely that people have non-inferentially justified beliefs about the measure in which certain complicated inference patterns make their conclusions probable. So, the belief that $E$ makes probable $P$ will be inferential and depend for its justification on other propositions or evidence. Now we have the proposition $P^{\prime}$, namely ' $E$ makes probable $P$ ', which is believed on the basis of another proposition or evidence $E^{\prime}$. To be justified in believing $P^{\prime}$ one must be justified in believing $E^{\prime}$ and also justified in believing that $E^{\prime}$ makes probable $P^{\prime}$ (i.e., that $E^{\prime}$ makes probable that $E$ makes probable $P$ ). The regress seems unavoidable.

We shall restrict our comment to beliefs about the past. As Fumerton suggests, scepticism about our access to the past is probably more damaging than, and logically prior to, scepticism about the external world. So, let us see how this works when $P$ is a proposition about a past fact or event which is believed on the basis of memory. $P$ would belong to "an interesting class of propositions about the past [which] have this feature: all of the propositions making up their evidential base are reports of apparent memories; and, it is assumed, they are obtained from this evidential base in a similar fashion" (Hookway 2000: 352). In our case, then, $E$ is something like 'I seem to remember that $P$ ', where $P$ is the corresponding proposition about the past. Am I justified in believing $P$ on that evidential basis? In order for me to be so, if we accept the PIJ, I must be justified in believing $E$ and also in believing that $E$ makes probable $P$. How can $I$ be justified in believing that $E$ makes probable $P$ ? Presumably (since the step from $E$ to $P$ is not deductively valid) on the basis on induction, of other cases in which my seeming to remember correlated with the fact $I$ then seemed to remember. But this new evidence on the basis of which I believe that $E$ makes probable $P$ is made out of propositions about past facts or events. And, by clause (1) of the PIJ, in order for this evidence to justify my belief that $E$ makes probable $P$, I must be justified in believing that evidence. But, since this evidence is made out of beliefs of the kind we started with, we are caught in a regress and cannot have justified beliefs about the past on the basis of memory. 
2. Hookway's strategy against Fumerton, as we see it, is an application of his general antisceptical strategy, as presented in some of his other writings. In his 1990 book, Hookway acknowledges his preference for a naturalistic epistemology. An essential aspect of his antisceptical strategy is his distinction between local and global normative epistemological assessments. Naturalistic epistemology allows for legitimate local normative questions about, e.g., the reliability of visual perception in particular circumstances of lighting. According to Hookway, "naturalistic epistemology may prove adequate to our needs if the only normative issues that need to be solved are local ones: they concern particular methods of inquiry against a firm background of theoretical and methodological certainty" (Hookway 1990: 237). Scepticism intrudes when local issues expand into global ones. Once we accept the global question, we soon realize that we lack the means to answer it. The question itself cuts the grass under our own feet and leaves us without defence against the sceptic.

In this context, Hookway's antisceptical strategy consists, in part, in emphasizing the differences in kind between local and global normative issues and in trying to block the expansion of local issues into global ones.

Another feature of Hookway's approach to scepticism is that, according to him, "the challenge of scepticism can be viewed as a special case of the free will problem" (Hookway 1990: 215). Scepticism challenges our rational autonomy as inquirers, preventing us from taking responsibility for our cognitive activities and their results. This connection between the problems of scepticism and free will gives rise to a distinctive, normative conception of justification. To say that someone is not justified in his beliefs is to imply that he has not acted, epistemically, as a responsible, selfcontrolled agent.

In his criticism of Fumerton's position, Hookway emphasizes again the difference between local issues, concerning particular conclusions which are drawn from a salient evidence against a background which is not put into question, and global issues, where the difference between salient evidence and background vanishes and extremely wide classes of beliefs (such as the class of beliefs about the past on the basis of memory) are examined. According to Hookway, the plausibility of the PIJ derives from its application to the former sort of cases, where it is little more than a platitude. However, when applied to the latter, this apparent platitude becomes a serious threat for the justification of large classes of our beliefs. Hookway attempts to block the passage from one sort of 
cases to the other while emphasizing the difference between them. He stresses the fact that the tendency to make broad classifications of beliefs goes with a substantive, nonnormative view of justification, whereas concrete specific classifications, not allowing an unrestricted spreading of sceptical doubts over wide doxastic areas, belong with the normative view of justification which he favours and we alluded to above. So, on this approach, "we explain what it is for a belief to be justified by reference to more fundamental notions concerning responsible deliberation and inquiry: a belief is justified when it is sustained by evidence and inquiry as (in some suitably qualified and reflective sense) it ought to be" (Hookway 2000: 362). Hookway opposes this view of justification to one (shared by Fumerton) which "views justification as a fundamental epistemic value or norm, one which can receive a substantial analysis" (2000: 362). Now Hookway will see the adoption of this second stance concerning justification as "a necessary condition for advancing from the platitudes embodied in the Principle of Inferential Justification to the sceptical arguments..." (Hookway 2000: 363), as far as it permits the construction of broad doxastic categories on the basis of uniform, very general patterns of justification, and, correspondingly, the raising of those global epistemological evaluative issues linked to scepticism.

We are sympathetic with Hookway's approach, but there may be some controversial points in it. Someone like Barry Stroud might probably find Hookway's attempt to block the slide from ordinary, local issues to global ones unsuccessful. According to Stroud, sceptical challenges do not make use of extraordinary, highly and implausibly demanding epistemic standards; they rather use, and follow naturally from, humble assumptions incorporated in ordinary, everyday assessments of knowledge claims (cf. Stroud 1984: ch. 2). Moreover, Hookway's criticism rests heavily on his normative view of justification and might be put in question if Fumerton's alternative view of justification could be successfully defended. Anyway, we are trying to follow a path parallel to Hookway's and to find an independent response to Fumerton's sceptical argument concerning the justification of our beliefs about the past. These two paths, however, might eventually join.

3. As we see it, the sceptical impact of the PIJ depends, among other things, on two assumptions, namely that all beliefs that $P$, where $P$ is a memory-based proposition about the past, are inferential and that the propositions which form their inferential base have roughly the form ' $I$ seem to remember that $P$ '. We shall 
dispute both assumptions. We think that Hookway concedes too much to Fumerton in that he seemingly accepts Fumerton's contention that all beliefs about the past are inferential. We are not convinced that this is true. Moreover, we shall also dispute the claim that our beliefs that $P$, where ' $P$ ' expresses a proposition about the past, are the result of inferential steps from apparent memories (or seemings to remember) that $P$ to $P$ or to beliefs that $P$. We shall contend that we simply do not do such inferences.

There are inferential beliefs about the past. We sometimes genuinely infer that something happened or that we did something from some piece of evidence. Suppose, for example, that I find, in the pocket of an old jacket of mine, a sales ticket from a shop in Teruel. On it appears the name and price of a certain article (say, a pot of honey). Now I remember I was in Teruel by the time indicated on the ticket, but I do not remember having bought that article. I still do not remember having done that, but I infer that I did from the information contained in the ticket and my memory of having been in Teruel. My belief that I once bought a pot of honey in Teruel is an inferential belief about the past. However, it does not show the inferential pattern indicated in the last paragraph.

Suppose, however, that in seeing the ticket I distinctly remember having bought the pot of honey. In this case, the ticket is not evidence from which I infer that I bought the honey, but an occassion or cause of my remembering. In many cases we just remember that $P$. So, for instance, while I am writing this, I try to recall what I did yesterday and I clearly remember that I gave a lecture on the free will problem. Do I infer that I gave that lecture? Not in the sense in which I infer that I once bought a pot of honey in Teruel from the ticket I found in my jacket. True, I have vivid memory images of my lecture, of the students who were present, of some questions they asked, and so on, but this is just remembering my lecture, not evidence from which I infer that I gave that lecture. And remembering I gave that lecture is, ipso facto, believing (and knowing) that I did.

"But," so the sceptic argues, "might it not be that you had those vivid memory images and you did not give that lecture? If you say 'yes', as you should, then you should not assume that in having those images you are remembering your lecture, but only that you seem to remember it, and your belief that you did it is an additional, not yet justified step". The answer might go as follows. That $P$ may be false does not mean that I merely seem to remember. Certainly, if $P$ is false, I do not remember that $P$, I 
maybe only seem to remember. But if it is true, I remember that $P$, I do not merely seem to remember. The sceptic will object that the truth of $P$ is something I have access to only through memory, so I cannot know whether I remember or merely seem to remember that $P$. I am not allowed to assume that I remember that $P$. Now the answer is that it is not true that memory is my only access to the truth of $P$. Today (when I am writing this) is Wednesday, yesterday it was Tuesday, and I have my timetable of lectures which confirms my belief. Besides, I can ask some of the students whom I think were there. Many memory based beliefs can be checked often by the testimony of other people or by observation of present objects or events.

But there are intermediate cases in which I would not say I infer that $P$ or that I remember that $P$ but only that I seem to remember, or that it seems to me that I remember, or that I think I remember, that $P$. It is important to notice that, contrary to Fumerton, these are only part of the cases where we form beliefs about the past. But how do we form such beliefs in these cases? Suppose that I seem to remember that I gave back to a friend some money I owed to him. It seems to me I did that while having a drink with him. I do not dare to say that I remember or that I know this. Do I form the belief that I gave the money back to my friend? It would be irresponsible for me to do so. The right thing to do is, maybe, to assign some initial probability to that proposition and to try to check it, or to modify such probability by investigating further. Maybe I try to recall what I did in the bar with more detail and stumble on a clear memory which confirms that proposition. Imagine I suddenly remember that another friend of mine told me: "Don't you have some money for me too?". This would be evidence that I was then giving the money back to my friend and I may form an inferential belief to that effect. Or maybe this vivid memory makes me have a clear 'visualizing' of the event. In the latter case, we have a case of remembering: I go from "I seem to remember that $P$ " to "I remember that $P$ ", but this is not an inferential step. From a certain moment on, I simply start remembering that $P$. My remembering the episode of my other friend causes me to remember what I started merely seeming to remember, namely that I in fact gave back to my friend the money he had lent me.

4. We have seen only some among a wide variety of cases of forming beliefs about the past on the basis of memory. As we can see, 'forming beliefs about the past on the basis of memory' does 
not name a uniform and unitary process. We sometimes use some actual evidence (the sales ticket) to infer that we did something or that something happened. We sometimes use something we remember to infer other things we do not remember. Other times we simply remember. And still other times we are caused to remember, so that we suddenly start remembering what we merely seemed to remember. And surely more patterns could be found. Fumerton, however, insists on considering all beliefs about the past on the basis of memory inferential. This erases all the differences we have drawn and leaves us with the unitary, uniform pattern of belief formation we are already familiar with: there is a certain evidence $E$, constituted by apparent memories that $P$, as well as an inference from $E$ to $P$. If we accept the PIJ, then in order to be justified in believing $P$ we must be justified in believing $E$ and also justified in believing that $E$ makes $P$ probable. As we saw, scepticism about the justification of our memory-based beliefs about the past is the likely result of these requirements. Fumerton construes a broad category of 'beliefs about the past formed on the basis of memory'. How could the different cases we have distinguished be accommodated into a general category of that sort?

If this characterization of what Fumerton has in mind is right, it probably, and paradoxically enough, leaves aside cases of properly inferential beliefs about the past, for, in some cases, their evidential base is not an apparent memory (the sales ticket case), and, when it is (as in the case where I remember the words a friend said to me), the inference pattern is very different from those cases of memory-based beliefs Fumerton seems to have in mind. In the former, I infer, from a proposition $P$ ('a friend was telling me: "Don't you have some money for me too?"), a different proposition $Q$ ('I was giving some money back to my other friend'), whereas in the latter the object of the remembering (or of the seeming to remember) is the same as the object of the belief, namely $P$ : I believe that $P$ and I remember (or seem to remember) that $P$. Is it true that $\mathrm{I}$ infer my belief that $P$ from my remembering that $P$ ? We do not think it is. Remembering that $P$ is, ipso facto, believing that $P$. No inferential step is involved. Maybe there is, however, an inferential step from ' $I$ have an apparent, experiential memory that $P$ ', or from ' $I$ seem to remember that $P$ ', to my belief that $P$. Is there? The fact that I can point to an experiential, apparent memory that $P$ to ground my belief that $P$ does not show that $\mathrm{I}$ infer that $P$ from such an apparent memory. The source of my belief is not (or not always) 
a premise from which I infer what I believe. It should make us doubt that an inference is involved the fact that the object of the apparent memory is the same as the object or content of the belief, for in a real inference there is at least a formal difference between premises and conclusion. But maybe the premise is the whole proposition 'I have an apparent memory that $P$ ' and the conclusion is ' $I$ believe that $P$ ' (or maybe ' $P$ '). What sort of inference is this? (Recall that we are not dealing with truth, but with justification of beliefs). There is, as it seems, a change of the attitude towards the proposition $P$, from 'having an apparent memory' to 'believing'. Now, if the 'apparent memory' is of the kind that, if true, we call 'remembering', it also includes 'believing', just as 'knowing' does. No true inferential step is involved. And if the 'apparent memory' is of the kind we would ordinarily call 'seeming to remember', then, in order to change the attitude to 'believing', we should try to find more evidential support for $P$ (an evidential support which is not, and does not contain, $P$ itself) before coming to believe it; otherwise we will be irresponsible or irrational. So, it appears that we simply do not do the sort of inference Fumerton is thinking of, namely an inference from ' $\mathrm{I}$ have an apparent memory that $P$ ' or 'I seem to remember that $P$ ' to ' $P$ ' or to 'I believe that $P$ '.

Fumerton probably thinks that there is a common state of 'seeming to remember' both when our memories are true and when they are false. This is a common move in internalist, representationalist theories of perception: truly perceiving and hallucinating share a common core, say, a 'seeming to perceive', and how they differ is something we do not have access to. But if this is what lies behind his sceptical move based on the PIJ, then we have scepticism in its traditional shape. Now, the common core thesis is no platitude; it is substantial and should be given independent support, for "seeming to remember" does not have here its ordinary meaning; it is intended to refer to a new, postulated kind of state. We will agree that a commitment to an analogue of sense data in memory is everything but uncontroversial. But once we make this commitment, any attempt to justify our belief that our evidence (understood exclusively as our putative seemings to remember) makes $P$ more probable than a sceptical, incompatible alternative is, for familiar reasons, likely to fail. Hookway's strategy, addressed to avoiding the rise of such global challenges, would be worth exploring again in this more traditional setting. But this takes us too far from the paper we are commenting on. 


\section{Notes}

*Research for this paper has been funded by the Spanish Government's DGES as part of the project PB96-1091-C03-02. Our thanks to this institution for its help and encouragement. We are also grateful to the organizers of SOFIA's 11th conference, Enrique Villanueva, Lourdes Valdivia and Luis Valdés, for inviting us to take part in it, as well as to our colleague Josep Corbí for his comments on previous drafts of this paper.

\section{REFERENCES}

Fumerton, R. (1995), Metaepistemology and Skepticism, Rowman \& Littlefield, Lanham, MD.

Hookway, C. (1990), Scepticism, Routledge, London.

Hookway, C. (2000), 'Scepticism and the Principle of Inferential Justification', this volume.

Stroud, B. (1984), The Significance of Philosophical Scepticism, Oxford University Press, Oxford. 